Journal of Southeast Asian

\title{
Health Perceptions and Practices of Burmese Refugee Families: A Participatory Mixed Method Study
}

\author{
Suneeta Kercood \\ Butler University, skercood@butler.edu \\ Trish Morita-Mullaney \\ Purdue University, tmoritam@purdue.edu
}

Follow this and additional works at: https://docs.lib.purdue.edu/jsaaea

\section{Recommended Citation}

Kercood, Suneeta and Morita-Mullaney, Trish (2015) "Health Perceptions and Practices of Burmese Refugee Families: A Participatory Mixed Method Study," Journal of Southeast Asian American Education and Advancement. Vol. 10 : Iss. 1, Article 8.

DOI: $10.7771 / 2153-8999.1124$

Available at: https://docs.lib.purdue.edu/jsaaea/vol10/iss1/8

This document has been made available through Purdue e-Pubs, a service of the Purdue University Libraries. Please contact epubs@purdue.edu for additional information.

This is an Open Access journal. This means that it uses a funding model that does not charge readers or their institutions for access. Readers may freely read, download, copy, distribute, print, search, or link to the full texts of articles. This journal is covered under the CC BY-NC-ND license. 


\section{Health Perceptions and Practices of Burmese Refugee Families: A Participatory Mixed Method Study}

\section{Cover Page Footnote}

We would like to thank the Butler University Awards Committee for their generous support of this photo voice project. We would also like to thank the interpreters form this project who were instrumental in engaging participants. Finally, we offer our sincere thanks to Dr. Katie Brooks of Butler University in conceiving the Photovoice portion of this study. Her vision for innovative ways of empowering participants is a gift. We thank you Katie. 


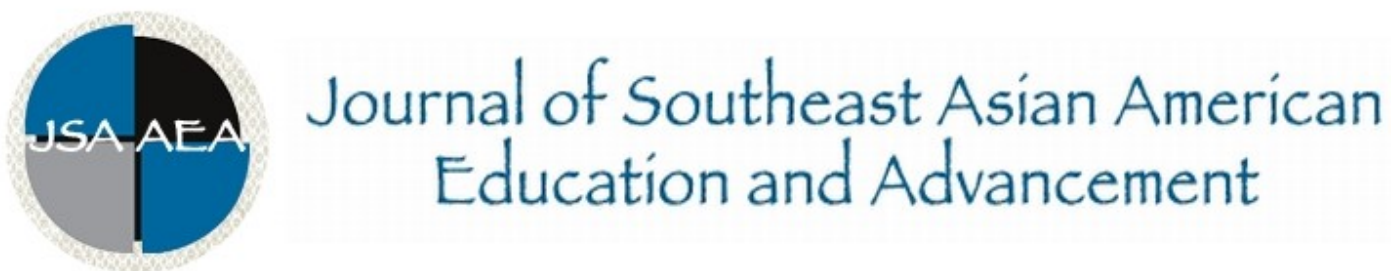

Volume 10 (2015)

Www.JSAAEA.org

\title{
Health Perceptions and Practices of Burmese Refugee Families: A Participatory Mixed Method Study
}

Suneeta Kercood

Butler University

Trish Morita-Mullaney

Purdue University

\begin{abstract}
Healthcare providers in the United States often view the lifestyle choices made by refugees from Burma through the lenses of America's norms for healthy living. Although healthcare providers often recognize the role that language plays in the refugees' ability to communicate their healthcare needs, they often ignore the role of culture. This lack of understanding of cultural difference contributes to the marginalization of refugees in the healthcare system. Using a transformative mixed method methodology, this study employed the East Asian Acculturation Scale (EAAM) to identify participants' perceived level of acculturation within health care contexts. The researchers then engaged participants in a qualitative exploration of their lifestyle choices using a Photovoice protocol. These two methods, girded by critical and ecological theories, elucidate the participants' counter-stories that provide insight into how the refugees are negotiating culturally relevant lifestyle choices in their new American contexts.
\end{abstract}

\section{Introduction}

Healthcare providers in the United States often view the lifestyle choices made by refugees from Burma through the lenses of America's norms for healthy living. Although healthcare providers often recognize the role that language plays in the refugees' ability to communicate their healthcare needs, the role of culture needs deeper examination. Using a transformative mixed method methodology, this study employed the East Asian Acculturation Scale (EAAM) to identify participants' perceived level of acculturation within health care contexts. The researchers then engaged participants in a qualitative exploration of their lifestyle choices using a Photovoice protocol. These two methods, author(s) and the Journal of Southeast Asian American Education \& Advancement, it is distributed for noncommercial purposes only, and no alteration or transformation is made in the work. More details of this Creative Commons license are available at http://creativecommons.org/licenses/by-nc-nd/3.0/. All other uses must be approved by the author(s) or JSAAEA. Journal of Southeast Asian American Education \& Advancement, Vol. 10 (2015) ISSN: 2153-8999 
girded by critical and ecological theories, demonstrate the participants' narratives that provide insight into how Burmese refugees are negotiating culturally relevant lifestyle choices in their new American contexts.

\section{Statement of the Problem}

The institution of translators and interpreters is a common response in facilitating the health related needs of immigrant and refugee communities. Although interpretation and translation is an initial response to make a healthcare exchange accessible, its orientation is technical in nature and does not examine the background experiences of its patients and how they experience their healthcare in the U.S. and how healthy living is conceived by them. While research on health disparities is extensive on the refugee community, very few studies examine the experiences of the Burmese community. This study intends to address this area through its unique mixed method design and participatory framework with and among the Burmese community of Indiana.

\section{Literature Review}

Health disparities are very commonly noted in the refugee population. By definition, refugees are individuals who have fled their country of origin with a well-founded fear of persecution due to their culture, religion or political opinion (United Nations High Commission for Refugees, 2010). As a result of the migration process, refugees can have serious mental health problems, such as depression, schizophrenia, posttraumatic stress disorder (PTSD), and psychosis (Beiser, 2005; Bhui et al., 2003; Grisaru, Irwin, \& Kaplan, 2003; Li \& Browne, 2000; Lin \& Cheung, 1999; Shepard, 1992; Thurston \& McGrath, 1993). Refugee children and families are often in lower socio-economic situations and many live in extreme poverty (Beiser, Hou, Hyman, \& Tousignant, 2002) and children from refugee families have higher rates of illnesses such as tuberculosis, intestinal parasites and other related conditions (Chambers \& Ganesan, 2005). Most refugees do not participate in health screenings and experience significant barriers in

accessing healthcare due to lack of understanding of the healthcare system, language, and culture. This leads to problems in continuity and consistency of care (Birman et al., 2008). Families often have different social and material resources to assist children in effectively navigating new education, health and social service systems (DéVoretz, Pivnenko, \& Beiser, 2004). This subtractive portrayal of their health inadequacies often promotes a model of fixing or remediating their poor health.

Numerous studies have addressed the relationship of acculturation and assimilation on the health of immigrants; however, there have been fewer studies examining this relationship among refugees. High acculturation level of Somalian refugees in various locations in the United States were significantly associated with greater use of preventive dental care (Geltman et al., 2014), prenatal care (Flynn, Foster, $\&$ Brost, 2011) and improvement in levels of food insecurity (Dharod, Croom, \& Sady, 2013) compared to similar refugees who were newer in the country.

Researchers have frequently reported that refugees struggle with mental health issues, such as post-traumatic stress disorder or depression (Fazel, Wheeler \& Danesh, 2005). Contrary to what might be expected, higher levels of assimilation may not 
necessarily lead to improvement, especially in mental health care for refugees. Among Eritrean and Sudanese refugees in Israel, it was noted that those who reported themselves to be assimilated reported higher depressive symptoms than those who considered themselves as being integrated (Nakash, Nagar, Shoshani, Zubida, \& Harper, 2012). Mental health issues were noted to be the likely cause of increased use of psychotropic drugs in refugees from Iraq, Iran, Eritrea, Ethiopia, Somalia and Afghanistan who had had longer duration of residence in Sweden compared to newer refugees (BrendlerLindqvist, Norredam, \& Hjern, 2014). Among young women from refugee populations and their attempts to assimilate in the new country, they tend to face higher levels of family conflict and poorer psychological health resulting from parental restrictions and expectations in the new country compared to their non-refugee counterparts (Koh, Liamputtong, \& Walker, 2013). Among adolescent refugees from Somalia living in the United States, for girls, greater Somali acculturation was associated with better mental health, whereas among boys, greater American acculturation was associated with better mental health (Ellis et al., 2010). Refugees have also reported devolution of their nutritional habits as a result of their extended stay in their new country, with increased access to fast food, limited options for fresh produce and fewer opportunities for physical activities (Rondinelli et al., 2011). Results of these limited numbers of studies indicate inadequacies, but also articulate that assimilation is not a panacea for health care access and healthy living.

Refugees or humanitarian entrants come to North America with sponsored and legal status. They are therefore, eligible for public assistance including food stamps, housing and Medicare (Exodus Social Services, 2014; United Nations High Commission for Refugees, 2010). Although this is a beneficial condition for refugee families, availability does not always promote culturally responsive accessibility. Agencies assist in identifying primary care physicians, but providers function within their same framework, utilizing the service of an interpreter to convey a standard health message (Johnson, Ali, \& Shipp, 2009; Kumar, 2013). This technical transference limits cultural responsiveness by diminishing it to a task orientation of "language translation only," ignoring cultural differences on perspectives for healthful living. Further, language translation is often conceived monolithically and distinct dialects may not be differentiated leading to a linguistic mismatch for Burmese patients (Vang \& Mong Trieu, 2014).

In addition to language differences, the focus on refugee infectious disease prevention and treatment creates a narrow view of refugee health. Refugees tend to have a higher rate of infectious diseases such as tuberculosis and the health arena reacts to ameliorate the spread of this infectious disease. This focus on communicable diseases can be a refugee's first experience with an American healthcare provider, creating immediate dissonance between provider and patient (Kumar, 2013). A medical model of tuberculosis uses the practice of surveillance, which seeks to establish methods for its eradication at the onset of immigration, but such interventions have found to have low impact (Kimbrough, Saliba, Dahab, Haskew, \& Checchi, 2012; Lobou \& Moser, 2004; Uppaluri et al., 2002). This diagnostic or medical model focuses on the presence of disease and creates mechanisms that serve to modulate and disquiet the refugee community, potentially invoking their own self-care for resolution (Foucault, 1995; Johnson et al., 2009; Kopecky, 2011; Kumar, 2013). 


\section{Background}

Since most of the research within the refugee population in North America has been limited to Canada, we explored their health within the U.S. geographical location of the Midwest. Currently, Indiana has seen a dramatic increase in the number of Burmese refugees resettled. In Indianapolis, the focal site of this study, 11,708 Burmese refugees have made primary or secondary settlements there, and is the largest host city in the state. The Burmese community is ethnically, linguistically and religiously diverse representing eight distinct groups, but the majority is Chin (Burmese American Community Institute, 2014; Vang \& Mong Trieu, 2014). Among the Chin, 31 different language dialects are spoken (Lewis, Simons \& Finning, 2015). In this site of study, Hakha Chin and Tedim from the Chin region of Burma are the most dominantly spoken. Burmese is a lingua franca, so most are multilingual (Barron \& Ranard, 2007).

In 2008, the local resettlement agency sponsored more than 400 persons, in 2009 more than 500 and in 2010 more than 650 individuals and their families. Refugee resettlement agencies are projected to resettle over 800 individuals in the coming years (Exodus Social Services, 2014). Additionally, refugees who were resettled elsewhere are increasingly making secondary migrations to Indiana because the local area is now considered a major Burmese refugee resettlement site and it is anticipated that the region will continue to experience growth (Burmese American Community Institute, 2014).

\section{Theoretical Framework}

Specific to this inquiry is the integration of critical and ecological theories, which grounds the interpretation and analysis of this inquiry. Critical theory grounds itself in examining unequal power relationships within locally situated systems, and in this case, the healthcare system (Crotty, 1998; Morrow \& Brown, 1994). As participants examine their experiences and assumptions about "normal" practices of healthful living, this reflexivity allows for an analysis of how the Burmese community are (re)defining the normalcy of healthy living. Critical theory pushes on the restrictive ways institutions interface with its clients and promotes perspectives that are multi-faceted with a particular focus on those that have been marginalized by such systems. This dialectic approach recognizes the presence of multiple perspectives, which are generative and potentially empowering for the participants (Greene, 2007; Mertens, 2003, 2009).

Complimentary to the systems perspective of critical theory, ecological theory focuses on how an individual is shaped by a system and how that person may inform, challenge, and transform the systems to be more responsive to their needs (Fielding, Teutsch, \& Breslow, 2011; Mertens, 2003). While these systems include socio-cultural, political, or physical environments, just to name a few of the possible contextual influences, relationships of power often govern these contextual factors (McLaren \& Howe, 2005). In fixed views of relations of power, the dominant culture will exert its influence over newcomers to the culture by defining its worldview and cultural practices as natural or normal. Conversely, in dynamic or ecological views of power, power is negotiated between the dominant culture and the newcomers, with both groups shaping the system (Bourdieu, 1984; Fairclough, 2001; Fielding, et. al, 2011; Smith, 2003) From 
this dynamic perspective on power, the newcomers can shape the healthcare system, to be more responsive and inclusive of their understandings.

Within the participatory design, we included participants in the data collection and analysis process. This approach mirrors the work of Mertens $(2003,2009)$ who addresses the ecological theoretical lenses within mixed methods research by attending to its focal participants at multiple stages of analysis and interpretation as they author the research. By examining how Burmese refugees are positioned by healthcare providers and how they situate themselves within these experiences, the theoretical paradigm is inherently participatory, emancipatory and transformative.

\section{Methodology}

This mixed methods study used a concurrent transformative design with data from a survey measure and interviews with the Burmese community (Canales, 2013; Creswell, 2003; Mertens, 2009; Sweetman, Badiee, \& Creswell, 2010; Zacharadias, Scott, \& Barrett, 2013). The quantitative survey tool, the East Asian Acculturation Scale (EAAM) of health perceptions (Barry, 2001) and a Photovoice protocol with semi-structured interviews were employed (Wang \& Burris, 2004; Wang, Morrell-Samuels, Hutchison, Bell, \& Pestronk, 2004; Wang, Yi, Tao, \& Carovano, 1998). Photovoice invites participants to photograph their lived realities around the research topic to contextualize and story their community health realities (Wang \& Burris, 2004). This qualitative portion is well suited for the question of inquiry and supports the emancipatory nature of this study. Responses from the survey were mixed with findings from participant captured photographs and accompanying interviews to represent the multiple ways that the Burmese refugee community is conceived institutionally and how they individually interface with their health needs. The qualitative findings are weighted more heavily in collection and analysis, consistent with this methodological design (Figure 1).

\section{Critical and Ecological Theories}

\begin{tabular}{|cc||}
\hline \multicolumn{2}{|c||}{ Concurrent Transformative Design } \\
quantitative $\Leftrightarrow$ QUALITATIVE \\
Demographic & Photovoice process \\
EAAM Survey & Individual and Focus Groups \\
\hline
\end{tabular}

Figure 1. Mixed Method Design.

A concurrent transformative design attends to a specific research goal that seeks to understand the needs of a marginalized community with the experiences that are relevant and meaningful to them. Participants construct meaning about their experiences individually and collectively as they develop shared meaning and a deeper understanding of their own cultural practices. In turn, they share this understanding with the researchers of the study. This focus creates opportunities for illumination and empowerment among those being studied (Mertens, 2003, 2009; Sweetman et al., 2010). 
This concurrent transformative study explored the following questions:

1. What are the perceptions of Burmese refugees in receiving medical/healthcare services?

2. What kind of dietary, exercise, and practices do they utilize to stay healthy?

3. What are the challenges in maintaining a healthy lifestyle in their new home?

The Institutional Review Board from the respective universities of participating researchers approved all research procedures and protocols.

\section{Participant Recruitment}

Participants were recruited by the researchers as a purposive sample of those of Burmese descent who came to the United States under refugee status and were taking English classes at an after-school program in an elementary school, and classes within an apartment community guest-house. The purpose and procedures of the project were explained to the individuals in the English classes, and they were invited to participate in the study. Those who provided verbal consent were then read aloud the written consent, with concurrent translations by an interpreter. This purposive sample is referenced as typical case sampling, which is best suited for the questions of inquiry when experiences are shared (McMillan \& Schumacher, 1997).

\section{Participants}

Participant recruitment procedures resulted in a sample of 10 participants, age range 25 46 years (five male and five female). Six of the ten participants also completed the EAAM survey and completed all sections of the demographic questionnaire. Seven of the ten participants participated in the in the qualitative, Photovoice portion of the study. Time of residence in the US ranged from two months to six years, and the education level of participants in their home countries of Burma ranged from some schooling (elementary/middle school) to some level of college education, (see Table 1). Given the low number of participants in the study, a statistical analysis was not conducted on quantitative data and was used to inform the more weighted qualitative portion. Photovoice studies of historically marginalized immigrant groups have utilized a small number of participants ranging from as few as four (Mejia, et al., 2013) to as many as 62 (Wang et al., 1998).

All participants were born in Burma, but represented a variety of religious and ethnic groups, including Hakha Chin, Burmese and Tedim and relocated to the United States fleeing for political, economic and religious persecution. The language representation was also diverse, most reporting that they knew some Burmese as a lingua franca, but nearly all speaking indigenous languages from the various areas in the Chin region (Table 2). 
Table 1

Demographic Information from the Participants

\begin{tabular}{|c|c|c|c|c|c|c|c|c|c|c|c|c|}
\hline ID & Gender & $\begin{array}{l}\text { Age } \\
\text { (in } \\
\text { yrs) }\end{array}$ & $\begin{array}{l}\text { Time } \\
\text { in } \\
\text { US }\end{array}$ & Education & $\begin{array}{l}\text { Current } \\
\text { Occupation } \\
\text { in the US }\end{array}$ & $\begin{array}{l}\text { Number } \\
\text { living in } \\
\text { current } \\
\text { Household }\end{array}$ & $\begin{array}{l}\text { Role in } \\
\text { Household }\end{array}$ & $\begin{array}{l}\text { Family } \\
\text { members } \\
\text { left in } \\
\text { Home } \\
\text { Country }\end{array}$ & $\begin{array}{l}\text { Current } \\
\text { Housing }\end{array}$ & $\begin{array}{l}\text { Any at home } \\
\text { have special } \\
\text { or medical } \\
\text { needs } \\
\text { YES/NO } \\
\text { (Explain) }\end{array}$ & $\begin{array}{l}\text { Have } \\
\text { Medical } \\
\text { Insurance } \\
\text { YES/NO }\end{array}$ & $\begin{array}{l}\text { Freq. } \\
\text { of } \\
\text { medical } \\
\text { visits. }\end{array}$ \\
\hline 1 & Female & 37 & $3 \mathrm{yrs}$ & $\begin{array}{l}\text { High } \\
\text { school }\end{array}$ & Unemployed & 5 & Mother & 11 & APT & No & Yes & $* *$ \\
\hline 2 & Male & 43 & $3 \mathrm{yrs}$ & $10^{\text {th }}$ grade & $\begin{array}{l}\text { Fixes } \\
\text { watches }\end{array}$ & 4 & Father & 6 & APT & No & Yes & Never \\
\hline 3 & Male & 46 & $6 \mathrm{yrs}$ & $\begin{array}{l}\text { Middle } \\
\text { school }\end{array}$ & $\begin{array}{l}\text { Works in } \\
\text { factory/ } \\
\text { production }\end{array}$ & 8 & $\begin{array}{l}\text { Lives with } \\
\text { Friends }\end{array}$ & 5 & House & No & Yes & Never \\
\hline 4 & Female & 40 & $5 \mathrm{yrs}$ & $4^{\text {th }}$ grade & Unemployed & 4 & Mother & $>10$ & APT & $\begin{array}{l}\text { Yes } \\
\text { Son has } \\
\text { asthma }\end{array}$ & Yes & $\begin{array}{l}\text { Every } 6 \\
\text { months }\end{array}$ \\
\hline 5 & Female & 28 & $5 \mathrm{yrs}$ & $\begin{array}{l}\text { High } \\
\text { School }\end{array}$ & $\begin{array}{l}\text { Factory } \\
\text { work }\end{array}$ & 4 & Mother & 4 & House & No & Yes & $\begin{array}{l}\text { Every } 6 \\
\text { months }\end{array}$ \\
\hline 6 & Female & 40 & $4 \mathrm{yrs}$ & $\begin{array}{l}\text { High } \\
\text { School }\end{array}$ & $\begin{array}{l}\text { Works in } \\
\text { Warehouse }\end{array}$ & 3 & Mother & $>10$ & House & $\begin{array}{l}\text { Son- thyroid } \\
\text { problems }\end{array}$ & Yes & $\begin{array}{l}\text { Every } 6 \\
\text { months }\end{array}$ \\
\hline 7 & Male & 25 & $2 \mathrm{~ms}$ & $8^{\text {th }}$ grade & Unemployed & 2 & Friend & 4 & APT & No & Yes & Not yet \\
\hline 8 & Male & 29 & $2 \mathrm{~ms}$ & $9^{\text {th }}$ grade & Unemployed & 2 & Friend & 3 & APT & No & Yes & Not yet \\
\hline 9 & Female & 33 & $3 \mathrm{~ms}$ & $\begin{array}{l}\text { Some } \\
\text { schooling }\end{array}$ & Unemployed & 5 & $* *$ & $* *$ & APT & $\begin{array}{l}\text { Yes- } 9 \text { yr } \\
\text { daughter } \\
\text { with eye } \\
\text { problems }\end{array}$ & Yes & $\begin{array}{l}\text { Every } 2 \\
\text { months }\end{array}$ \\
\hline 10 & Male & 38 & $* *$ & $\begin{array}{l}\text { High } \\
\text { School }\end{array}$ & Unemployed & 1 & $\begin{array}{l}\text { Lives } \\
\text { alone }\end{array}$ & 3 & APT & No & Yes & $1 \mathrm{x} / \mathrm{yr}$ \\
\hline
\end{tabular}

Note. Yrs $=$ Years; $\mathrm{ms}=$ Months; $\mathrm{APT}=$ Apartment; $* *$ did not answer; Freq. $=$ Frequency. 
Table 2

Language and Ethnicity of the participants

\begin{tabular}{lll}
\hline Participant & Languages & Ethnicity \\
ID & & \\
\hline 1 & Not reported & Not reported \\
2 & Chin Falam, Hakha, Mizo, Tedim, Burmese & Chin \\
3 & Hakha Chin & Chin \\
4 & Chin & Chin \\
5 & Burmese, Chin & Chin \\
6 & Burmese, Mizo & Burmese \\
7 & Tedim, Chin & Chin \\
8 & Zomi, Zalai & Chin \\
9 & Tedim & Chin \\
10 & Burmese & Burmese \\
\hline
\end{tabular}

\section{Materials and Data Collection Procedures}

Participants met three times within three months for 60-90 minute intervals. The first session was to introduce the study, obtain informed consent and complete demographic information. The second session, participants completed the EAAM scale and were trained on the use of the camera and how to conceptualize images for capture. The third session involved short interviews of 10-15 minutes with each participant about their captured images. One 90-minute focus-group discussion about the images they had selected as most salient in describing their health experiences followed. There were two focus groups discussions; one having four participants and the other having three. All interviews and small group discussions were audio recorded and transcribed by the researchers. Details of each of these activities are described in the following sections. Participants were given a $\$ 25$ dollar stipend at the conclusion of the study. The two interpreters were offered $\$ 50$ for their help, but they declined to accept. They were thankful that the researchers were addressing this area of need for the participants, and were glad to help in the project. An unintended outcome of the study was the beneficence that the interpreters sensed as a result of the collaborative research work.

Survey. The East Asian Acculturation Measure (EAAM) (Barry, 2001) is a 29-item selfreport questionnaire that contains four subscales (Table 3): assimilation ( 8 items; e.g., "I find that Americans understand me better than Asians do"), separation (7 items; e.g., "Asians should not date non-Asians"), integration (5 items; "I feel very comfortable around both Americans and Asians"), and marginalization (9 items; "I sometimes feel that neither Americans nor Asians like me"). Items are scored on a 7-point Likert-type response format (strongly disagree, disagree, disagree somewhat, neutral, agree somewhat, agree, agree strongly). The total score for each scale is derived by summing reverse-scored and positive-scored items. The higher the total score in each sub-scale, the higher the level of assimilation or separation or integration or marginalization respectively. The scales have demonstrated adequate internal consistency (Cronbach alphas of .76, .77, .85, and .74, respectively).

Barry (2001) posits that low acculturation is associated with East Asian patients not seeking care when necessary and that language and cultural differences impact the way health 
needs are expressed and conceived. It can be instructive in creating more culturally responsive services and practices (Vang \& Mong Trieu, 2014).

Table 3

East Asian Acculturation Scale (EAAM)

\begin{tabular}{ll}
\hline Item & Description \\
\hline Assimilation & $\begin{array}{l}\text { The degree to which one gives up their } \\
\text { native culture in favor of new Western } \\
\text { culture }\end{array}$ \\
Separation & $\begin{array}{l}\text { Maintenance of ethnic culture and absence } \\
\text { of relations with greater society }\end{array}$ \\
Integration & $\begin{array}{l}\text { The degree to which one's native culture } \\
\text { is maintained and new culture is fostered }\end{array}$ \\
Marginalization & $\begin{array}{l}\text { No contact and/or isolation with native } \\
\text { culture and new culture }\end{array}$ \\
\hline
\end{tabular}

Note. Adapted from Barry, 2001.

Photovoice training. The qualitative Photovoice component followed quantitative data collection. This Photovoice process invited participants to take pictures of their everyday representations of healthy living. This protocol allows participants to later discuss and interpret their current circumstances and imagine future possibilities for their healthy living in the U.S. Wang \& Burris (2004) and Wang, et al. (2004) posit that Photovoice can inform policy, institutional practices and empower participants in intellectualizing their healthy living. Participants were trained on the use of the digital cameras and how to view photos after capture. They were advised to take multiple pictures of images that represented content of healthy and unhealthy living in their daily lives. Participants were shown a variety of examples that represented healthy living, including a bowl of colorful fruits and vegetables from an area supermarket, a well-groomed sidewalk for walking and exercise and a doctor's office. Most were familiar with the camera's functions and were able to assist others who were not as technically proficient. Participants were given two weeks to capture the photographs. They then met with the researchers and interpreter(s) in short individual interviews followed by focus group discussion sessions.

Individual and focus group interviews. Photos captured are used as a data source in individual interviews and a collaborative group discussion to illuminate questions about their healthcare conditions, the efforts and understanding about healthy living and how they are situated institutionally by healthcare providers.

Interpretation. Two interpreters, proficient in English, Burmese and a variety of Chin dialects were recruited for the study. These interpreters were selected because they were recommended by the English language program staff as they served in support roles of the instructional program and were familiar and trusted by the participants. Prior to data collection, 
the interpreters were trained in the EAAM survey, Photovoice strategies and the overall scope of the study. This type of preparation with interpreters is necessary to understand the contextual and nuanced qualities of interviews involving translation and interpretation (Pochhacker, 2004). Consecutive translation was used with the primary investigators asking questions first in English followed by appropriate interpretation in the target language. Interviews and group discussions were conducted using the Photovoice protocol, and field notes were taken by the lead researchers.

\section{Data Analysis}

The data yielded from the EAAM survey provided information on the participants' perceptions about their assimilation, integration, separation and marginalization, whereas the qualitative Photovoice portion and the follow up individual interviews and focus group discussion demonstrated how they were experiencing and enacting healthy living.

EAAM survey. The EAAM survey, an attitudinal survey was analyzed using Barry's (2001) metric of levels and/or degree of assimilation, integration, separation and marginalization. Outcomes were aligned with participants' demographic characteristics to determine if there was a relationship between particular variables. Although the survey was administered concurrent with the qualitative data collection, it was not analyzed until after the collection of the qualitative data as co-analysis is central to this study's design. Discussion was held with participants to extend their explanations of their responses on the scale, mixing it with qualitative findings in the Photovoice portion.

Photovoice protocol. The participants engaged in participatory analysis of the qualitative Photovoice portion with the researchers and then their focus group. First, participants shared a selected image to the research team and offered a title or a caption for their photos and qualified it as an asset or challenge. Next, participants brought their captioned photo to the focus group, describing it in detail and providing a rationale for its selection. Focus group participants asked questions and connected the photos with their own experiences, deepening the interpretation. This process helped "identify the problem or the asset, critically discuss the roots of the situation, and develop strategies for changing the situation" (Wang et al., 1998, p. 80).

Finally, the researchers worked with participants through mixing the data from the quantitative and qualitative findings. The results from the EAAM survey were shared and compared and contrasted with Photovoice analysis. Participants identified where the quantitative survey was reflected within their stories and how the results differed from the scale. This complementary protocol of mixing quantitative and qualitative improves rigor (Stewart, Makwarimba, Barnfather, Letourneau, \& Neufeld, 2007) and attends to the central contributions of participants (Canales, 2013). Using inductive coding with the participants, themes were then collapsed with axial coding (Creswell, 2007; Creswell \& Plano Clark, 2007).

Johnson et al. (2009) used a conceptual theoretical framework as an interpretive tool throughout in a mixed methods study of Somali refugees with experiences of female genital cutting in an effort to understand their health-seeking behaviors. Although Johnson et al. (2009) did not use ecological theories, their study design was mixed methods and grounded in critical theory with an emancipatory focus for its participants. Building on Johnson et al.'s work and Merten's $(2003,2009)$ avocation for theory being conceived throughout the study, the following 
conceptual framework was created (Figure 2). Although Johnson et al.'s work did not specifically address a Burmese refugee community, the participants were recent refugees with conceptions of healthy living that differed from those they experienced in the U.S.

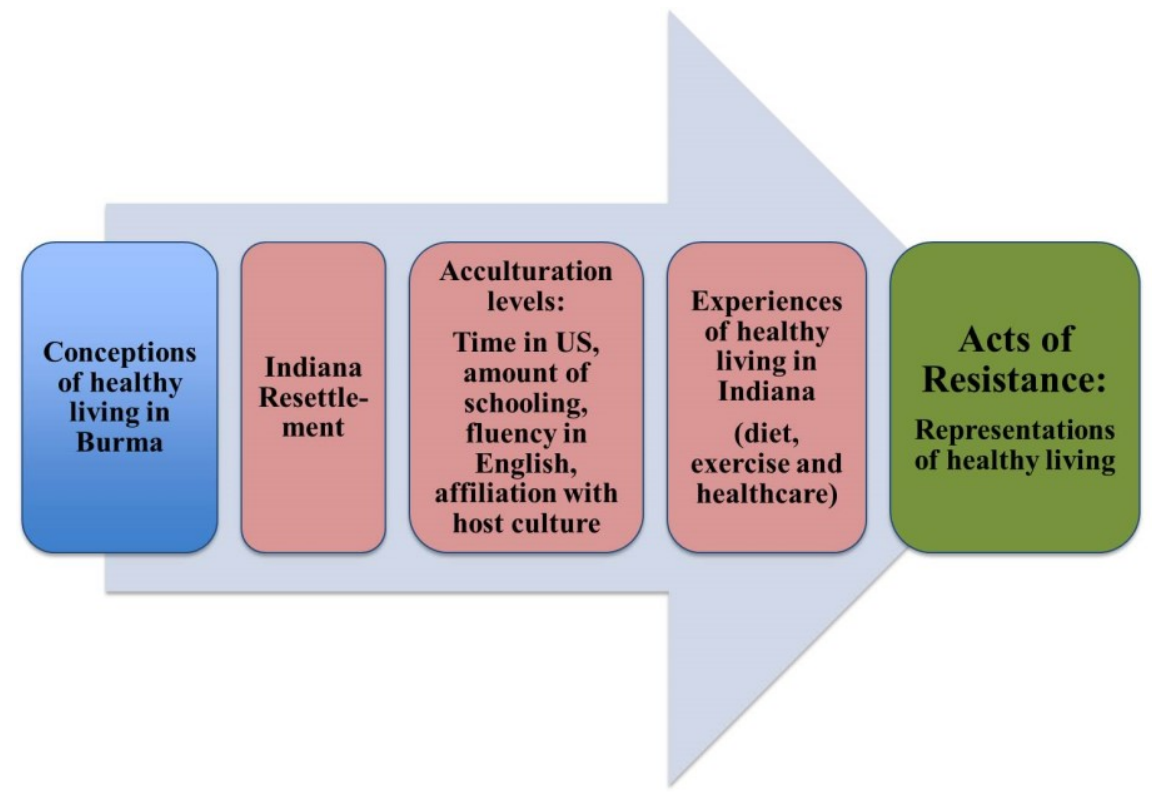

Figure 2. Conceptual Framework of Burmese Refugees and Healthy Living. Adapted from Johnson, Ali, \& Shipp, 2009.

This framework represented in Figure 2 articulates a likely timeframe of Burmese refugees' entry to the U.S. and the interfaces with healthy living. The pink rectangles denote the institutional practices and processes that the Burmese refugees negotiate. The last green rectangle identifies the experiences of the Burmese refugees blending their historic health experiences within new systems and how they are embodied. This conceptual framework assists with the visualization of the units of analyses, which for this study are the EAAMS survey and Photovoice protocol.

\section{Our Positionalities as Lead Researchers}

As researchers from local universities we inherently realize the immediate disequilibrium of power that can be sensed by the participant community. Although the instructors of the English program have told the participants to "trust in our work" we were consistently attentive to keeping their analyses central as they represented their stories. The researchers were Asian American and Eastern Indian, and this appeared to help build trust with the participants. 


\section{Results}

\section{Quantitative Findings}

Given the low number of participants in the study, a statistical analysis was not conducted on quantitative data and was used to inform the more weighted qualitative portion. This is consistent with an exploratory, transformative design.

EAAM survey. An analysis was conducted by the research team comparing the demographic characteristics of the participants to their perceptions of the various dimensions of acculturation within the EAAM survey. Years living in the U.S. had the largest impact on participants' perceptions of their sense of inclusion in their new home. Four of the seven participants lived in the U.S. three years or greater had moderate levels of integration and assimilation, yet separation and marginalization was moderate to high (see Figure 3).

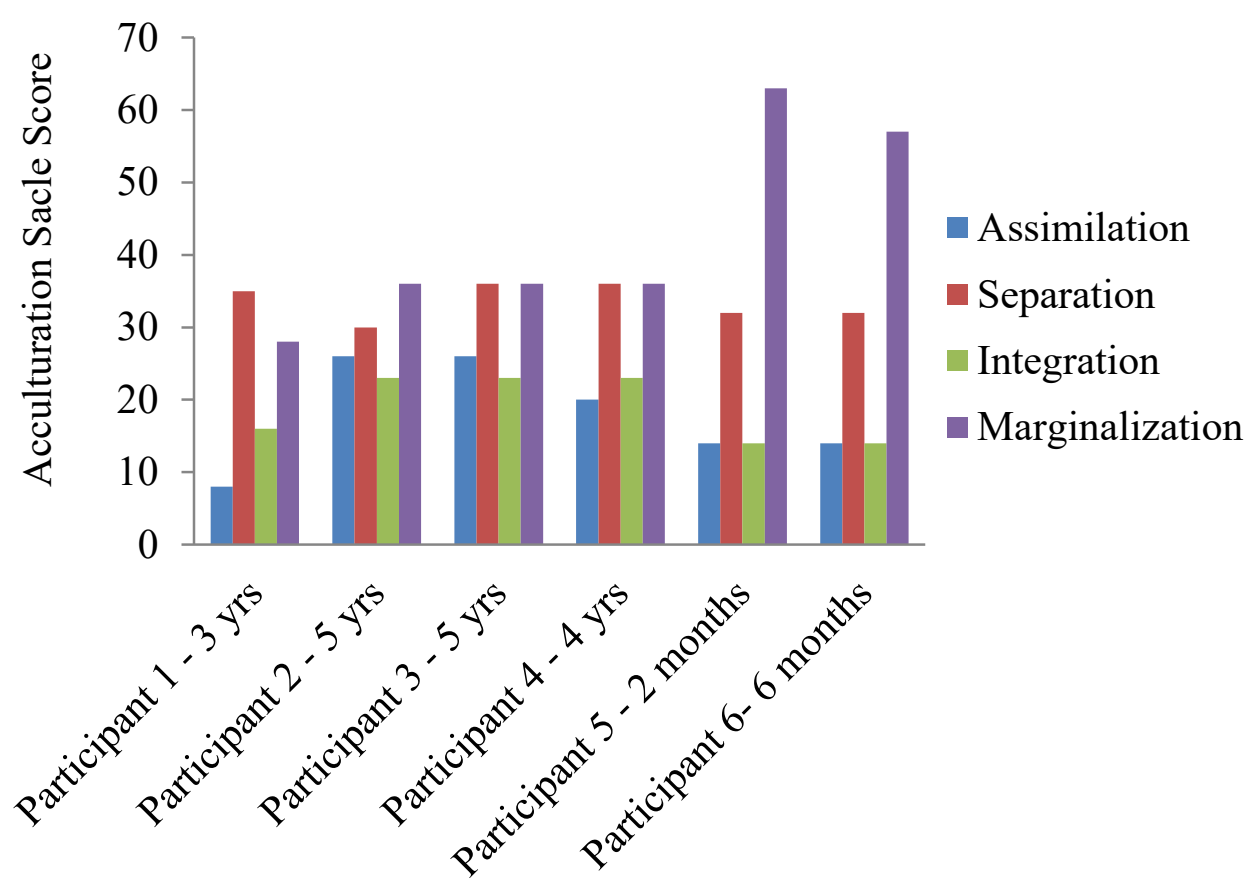

Figure 3. Years (yrs) / Months in the US and the Participants level of acculturation.

Participants five and six had been in the U.S. the least amount of time, ranging from three to five months and they perceived themselves as having low levels of integration and assimilation and higher levels of separation and marginalization. These two participants were also unemployed and actively seeking work.

In comparing the survey scores with education levels, four of the ten participants had some schooling (up to elementary/middle school), five completed high school, and one attended college but did not complete an undergraduate degree. Seven participants provided details on both their education levels as well the EAAM survey (Figure 4). Visual analysis of data based on 
years of education demonstrated that this had an impact on their level of integration and assimilation. Participants five and six had the lowest levels of education (some schooling), and demonstrated greater acculturation challenges in marginalization and separation. The remaining participants had either a high school or some college and most of them demonstrated higher scores in assimilation and integration (Figure 4).

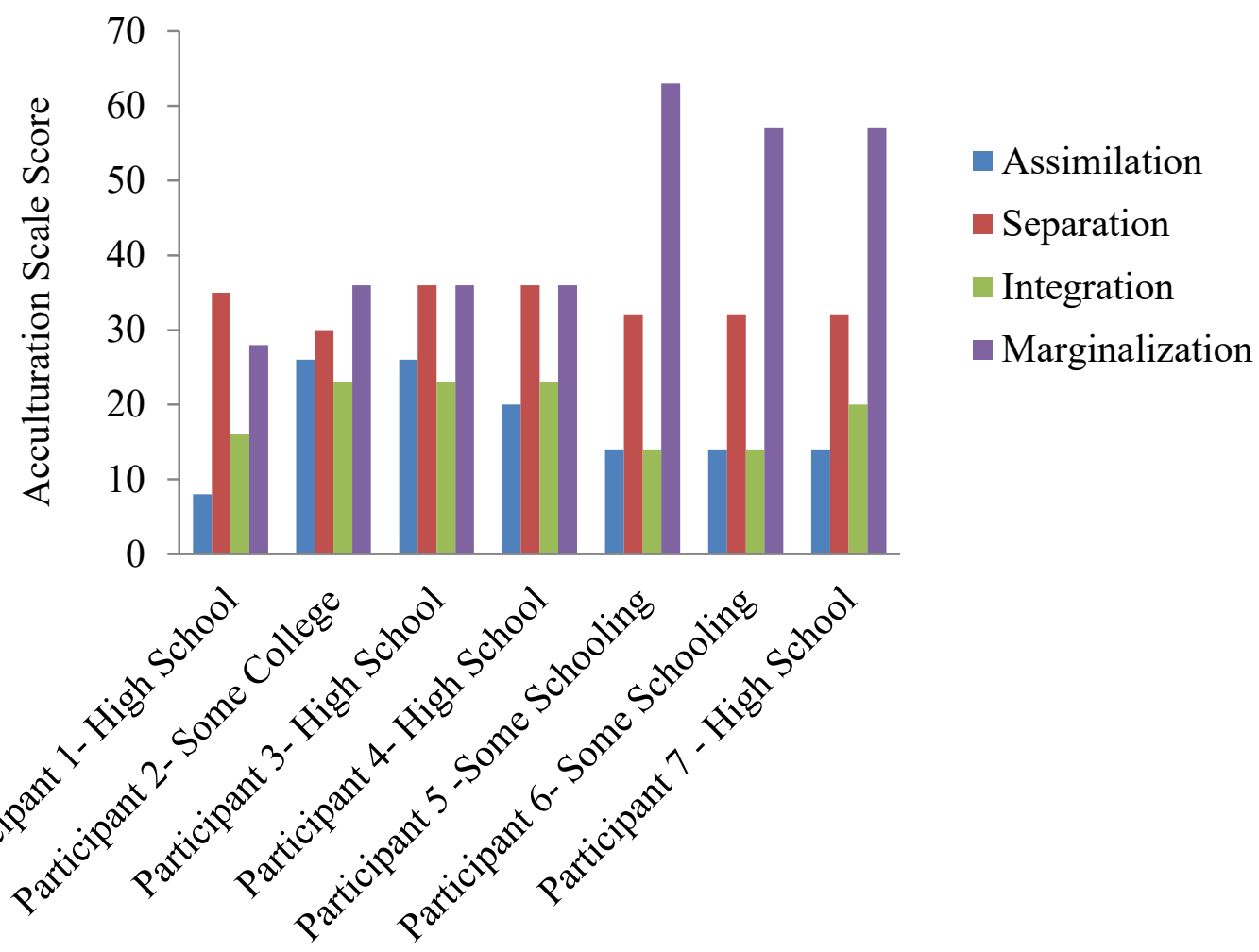

Figure 4. Participants' Education level and their levels of acculturation.

In examination of Barry's (2001) EAAM's survey, items related to assimilation largely relied on proficiency in English, which all participants were actively seeking to master. Integration items were associated with their perceived capacity to interact with individuals from dominant institutions, specifically healthcare providers, and institutionally available resources through local church agencies, social services, schools, their English classes and publically furnished healthcare. Separation and marginalization items attended to reciprocal interactions with individuals who they regarded as different from their own heritage and conditions, including healthcare providers. The systems and supports within the healthcare system availed to the Burmese refugee community are instruments to realize higher levels of acculturation. However, acculturation relies heavily on the variable of time to realize a greater sense of assimilation and integration, such as acquiring English and fostering relationships from cultures other than their own. For participants living in the United States for three to five years, a level of marginalization and separation strongly persists (Table 4). 
Table 4

Scores on East Asian Acculturation Measure (EAAM)

\begin{tabular}{|c|c|c|c|c|c|}
\hline & \multicolumn{3}{|c|}{ Scores on East Asian Acculturation Measure (EAAM) } & \\
\hline ID & Assimilation & Separation & Marginalization & Integration & $\begin{array}{c}\text { Total } \\
\text { Score }\end{array}$ \\
\hline 1 & 8 & 35 & 16 & 28 & 87 \\
\hline 2 & $* *$ & $* *$ & $* *$ & $* *$ & $* *$ \\
\hline 3 & $* *$ & $* *$ & $* *$ & $* *$ & $* *$ \\
\hline 4 & 26 & 30 & 23 & 36 & 115 \\
\hline 5 & 26 & 36 & 23 & 36 & 121 \\
\hline 6 & 20 & 36 & 23 & 36 & 115 \\
\hline 7 & $* *$ & $* *$ & $* *$ & $* *$ & $* *$ \\
\hline 8 & 14 & 32 & 14 & 63 & 123 \\
\hline 9 & 14 & 32 & 14 & 57 & 117 \\
\hline 10 & 14 & 32 & 20 & 57 & 123 \\
\hline
\end{tabular}

Note. Higher scores on the EAAM indicate higher participants' perception of the various dimensions of acculturation. $* *=$ Did not answer/complete the EAAM.

Participants resisted the description that amount of time in a new country and acquisition of a new language was predictive of assimilation, which could realize greater access to healthful living. Health was a daily and imminent need and as such, immediacy could not be reconciled by simply waiting for a sufficient level of acculturation to be acquired.

\section{Qualitative Findings}

Participants identified the following themes in the analysis of the individual interviews and focus group discussions using the Photovoice protocol. A discussion with the participants prior to capturing photos illustrated a tacit understanding of what they needed prior to finding healthy food to prepare and consume and realize improved comfort with healthcare providers. Time was identified as their major barrier to acquiring sufficient English to adequately navigate Englishspeaking food markets and healthcare systems. As time was not an adequate resolution to their expressed immediacy, qualitative findings revealed other interpretations that expanded the notions of waiting. The emergent themes are described as follows.

Lost in translation. Based on the reports of participants, area health centers and in particular, primary care doctors furnished interpreters (spoken) for the Burmese community when they had appointments. In emergencies, a service was solicited and someone came to interpret. One participant took a photo of a medical from (Figure 5). Forms were seldom in their native language, only being explained through a medical interpreter or a family member who could potentially explain the documents. Forms were seldom translated, so the reliance on spoken interpretation was central. One example of the comment made by a participant was as follows:

If they're (referring to the interpreter) a good person and they give it (referring to the medical forms) to me. I don't feel good if they fill it out. I should fill the form out before, 
so I don't get frustrated. The same day, I go and I don't speak English well, how can the interpreter know as well? They gave to me the same day.

Having to complete to a required health form ten minutes before she saw the physician was unsettling, as she felt she would be inaccurate and this could change the course of decisions made in the examination room (Figure 5). Having an interpreter availed to her created further frustration. She recalled her historic experiences:

Here is the problem is about the interpreter, even though they want to say something, if they want to say it, they may not. I've seen that a lot. They want to say it, by action, the patient shows by action, but the interpreter does not. If they want to say it, they will and if they don't, they won't.

As an interpreter was employed, the perception from the doctor was that his message had been received and understood by the patient. The function of the interpreter was insufficient and did not attend to the accuracy or the emotive story of her health concerns. This lack of thoroughness diminished her contribution and reduced the reciprocity that she anticipated between physician and patient. The doctor appeared oblivious to her, assured that the presence of an interpreter was adequate.

The participant went on to describe the interpreter having an economic incentive. He was paid for two hours regardless of the time that he spent with her. She inferred that the interpreter was motivated to conclude quickly, so he could move onto his next assignment, being paid for two hours for ten minutes of work. This created unanticipated tension where she felt betrayed by a Burmese national who she originally conceived as a supporter. She conceived the doctor as the content specialist and complaining about the interpreter's accuracy was not a domain she felt the doctor could influence.

Furnishing a technical solution of "language only" support created an unequal relation of power between doctor and patient, and patient and interpreter. The participant self-identified a need for medical care and interpretation, but this promoted a transmission model of language that ignored the complexity of her health condition.

Another participant added to the translation and interpretation dilemma with his photograph of a clock (Figure 6). As a senior member of the Burmese community, he was frequently called upon by other Burmese to intervene in health situations of immediacy. He was regarded as a Burmese patient advocate within his community. He described the ill state of a friend that he accompanied to the emergency room. He said:

My friend is very seriously ill. Blood sick... and he threw up blood. I checked at the counter and everything and he kept throwing up blood and they didn't call us. My friend almost died on that night, there were no other patients in the waiting room, but when I talk about that, whenever Burmese go to the emergency room, we wait. 


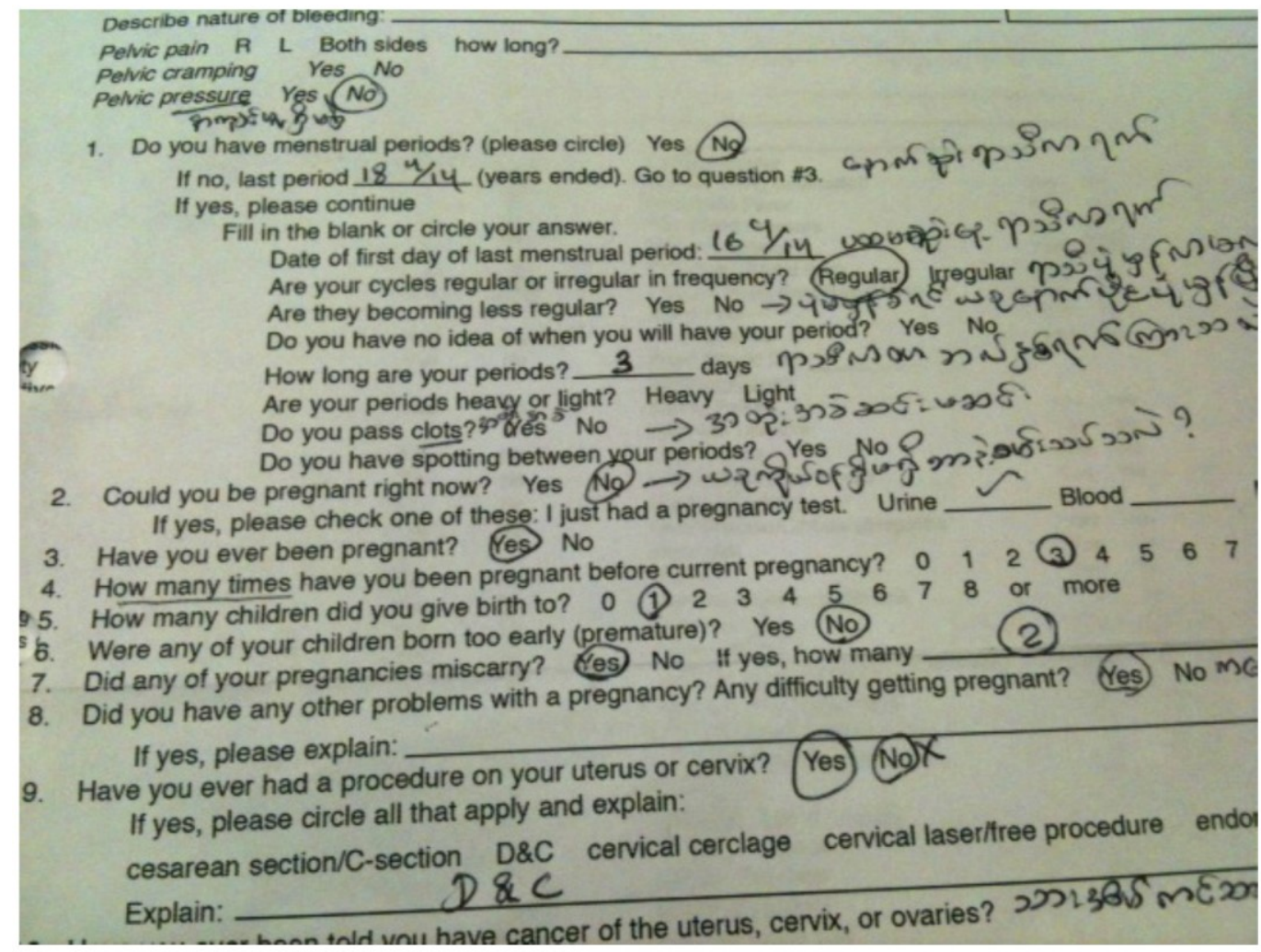

Figure 5. The "Form."

Figure 6. "The Clock."

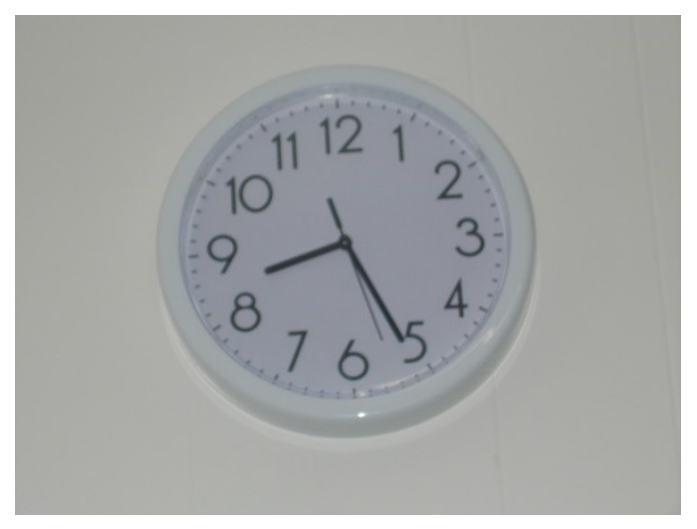

The representation of the clock was a reoccurring theme with the participant who frequented the emergency room. His understanding was that emergency rooms were for immediate care and an appointment was not needed. Although he did not speak English well, he conveyed that vomit and blood should be sufficient for attention, but the consistent response at the front desk was to wait longer. After having multiple experiences of long wait times, he concluded that the Burmese were the ones that had to wait. He asserted, "I want to understand how this emergency room works!" As an ambassador to his community, he felt he could not serve in his senior and esteemed role because the institution had collectively excluded him from a timely response.

This Burmese patient advocate found that his unique skill and identity in this revered role collided with what he believed was a collective inscription of him as "Burmese" and having to 
"always wait." He had a clear devotion to wanting to understand the system and despite the use of a hospital-furnished interpreter, more wait time persisted as the response.

Naming as a form of resistance. Although names of places such as the doctor's office and area health clinics were translated for the Burmese refugees in three dialects with their sponsoring refugee agencies and reinforcement from their adult English program, Burmese refugee participants offered different understandings. One participant remarked on her experiences of immunizing her family upon arrival to the U.S. She discussed the role and name of a comprehensive health clinic she visited upon her arrival: "They give immunizations ... and then they check if they have the TB or anything and that kind of stuff. The doctor checks for that." This participant identified area health clinics supported by her Medicare plan as the "immunization place." The participants' first memories of receiving healthcare in Indianapolis were a battery of immunizations and injections. Regarded as the first stopping point for healthcare upon their arrival, one participant described the health center's myopic focus.

They give me appointments for immunization appointment. On that day, my child has a fever. We had to take (child) to the doctor for the immunization and when they don't give him a shot, the doctor is supposed to see him and give him medicine, so we don't like going there a lot.

When the doctor at the clinic did not prescribe medicine for their child's fever and informed them that they would receive the required immunizations later, the participant and her spouse conceived the "immunization place" as lacking immediacy for them individually while protecting the narrow focus of vaccinations. This institutional preservation in scope and purpose led to a disdain for doctors and staff working in the "immunization place."

By naming the "immunization place" they resisted the prescribed focus of its expressed purpose and scope. They shared their concerns about the clinic with other Burmese friends and families. They created a navigation system, leading them to more individual and responsive care, seeking out their primary care physician in lieu of the area clinic.

From fresh to frozen. Participant captured photos of refrigerators revealed produce that would be regarded as fresh by North American standards. Other photos captured flash frozen fruits and vegetables in the freezer section. One was a frozen durian, a Southeast Asian delicacy eaten at special times: "my employer told me that if you can eat [durian] once a day, that is very good for your body, healthy skin and everything. But, whenever we have money, we eat it." He was excited to find durian at a large scale Asia-mart when he arrived, but because it was frozen, it didn't have the same taste or texture of fresh durians that he previously enjoyed.

Another participant also remarked on the difference between the fresh durians of Burma and the frozen ones in the local Asia-mart: "It's different ... Frozen one is not very good to suck. But, from the tree where I got right away, it's very good to suck." The participant enjoyed acquiring durian at the store and bought it more frequently than he would in Burma because of its availability and reasonable price. Even though its flavor was impacted by its frozen state, changing how he enjoyed it, he still found that it had a place in his palette as it represented a healthy purpose for good skin care and anti-aging (Figure 7). 

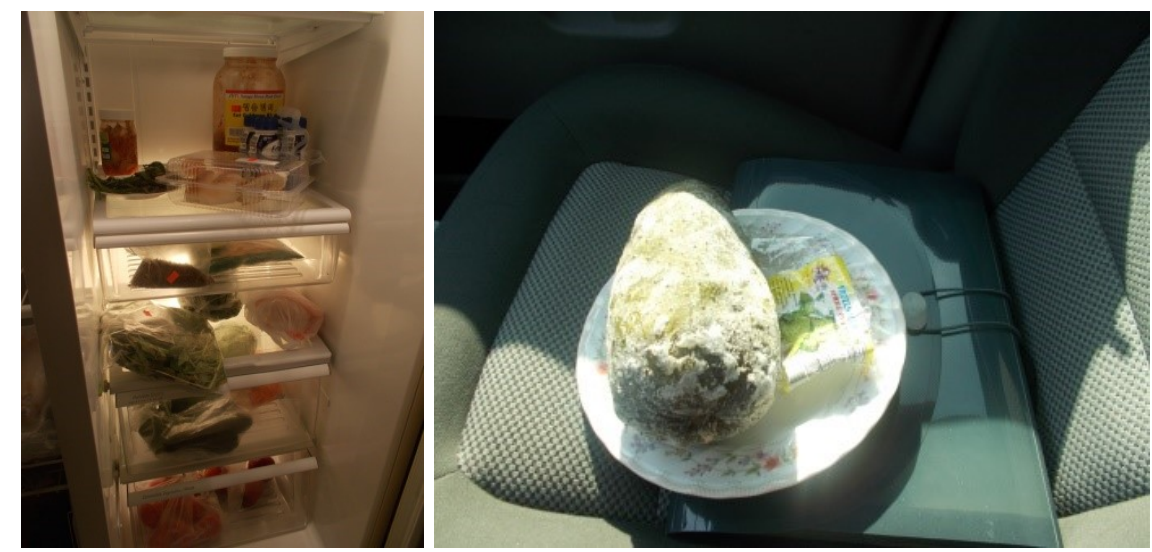

Figure 7. Fresh and Frozen.

Not my food pyramid. One participant took photos of a Halal ${ }^{1}$ Meat section sign at a local Asia-mart and of a diagram of the food pyramid of the U.S. Department of Agriculture. This food pyramid provides a visual model for diets being dense in grains, fruits and vegetables with lesser representation of fatty foods (Center for Nutrition Policy and Development, 2005). Its purpose is to promote balanced food consumption for overall health and weight management. Regarded as a compass for healthy eating, it was viewed as restrictive to a Muslim participant who ate halal prepared meats.

This participant remarked on the consistent review of the "food pyramid" when she went to her primary care physician with her children. She reflected on what she was preparing her children at home as a Muslim Burmese and felt that the "halal" preparation that she employed violated the strict food pyramid. A researcher asked if it was easy to find halal prepared meat. One participant remarked, "No. It's easy the vegetables and fruits, but chicken it's not easy. We are Muslim and we just eat the meat, the halal." Although a regional Asia-mart has halal prepared meat, it was distant and costly. Further complicating the acquisition of halal meat, was the food pyramid that was consistently shown during her doctor's visits with her children (Figure 8). She did not use the food pyramid, but felt pressure to impose it to meet the healthy living standards for her doctor.
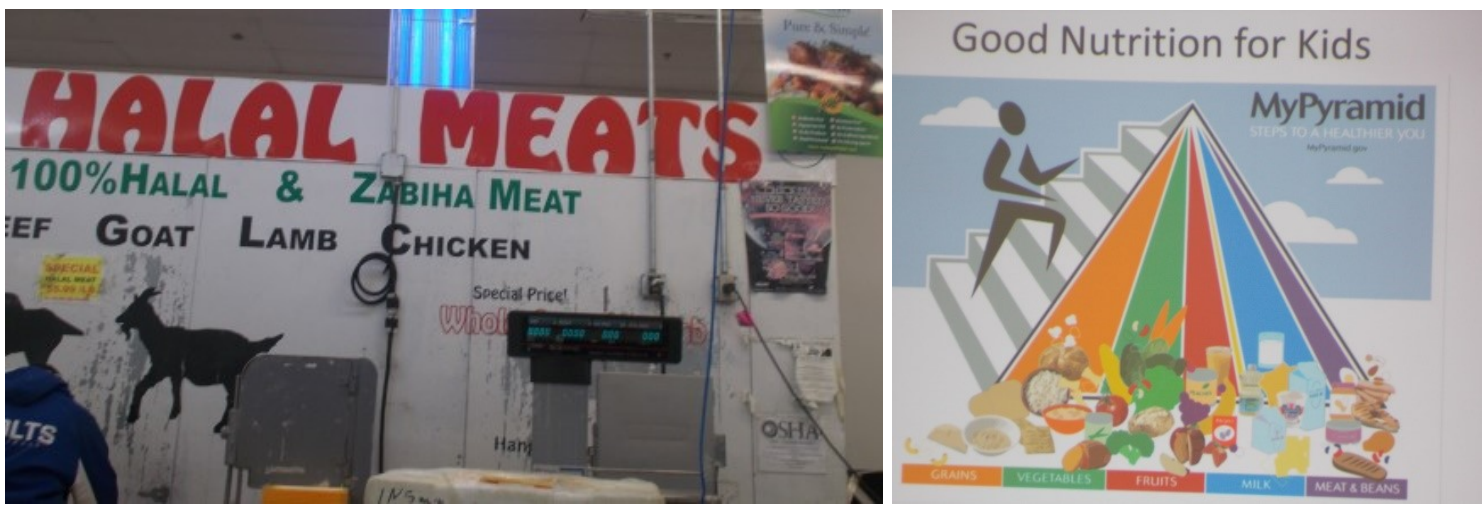

Figure 8. Halal and the Food Pyramid.

\footnotetext{
${ }^{1}$ Halal references permitted or lawful, but is specific to the dietary customs of Muslim followers. Pork or pork products, animals that were dead prior to slaughter or animals slaughtered improperly are considered a violation of halal preparation.
} 
Healthy consumption of food was conceived within a tight and fixed pyramid. Diets conceived within cultures other than the U.S. and from religions that were locally unfamiliar situated the Burmese as not being as healthy. Mere adjustments were necessary and she would meet the healthy living standard deemed proper by her doctor. Simplifying these dietary changes within the paradigm did not consider her religion, history and identity, which she felt were conscious decisions and not mere choices. The doctor had a technical orientation of health, asserting that good health was simply a matter of a few changes and driven by a menu of "choices," on the food pyramid.

Exercise and physical activity. Participants reported that their physical activity was reduced since their relocation as they were limited to borrowing a car, being driven by a case worker or taking a public bus that did not have the frequency or reliability of which they were accustomed. Also, due to inclement weather, being able to ride a bike was only available during warmer months: "So, it's not the same, not only when we work and exercise. In Burma, there's the bus that people take and then walking and bike that we ride." Two female participants also remarked that the rules for riding in a car differed as children had to sit in their own seats, in the back and if young, they had to be in an appropriate car seat: "In Burma, kids can sit in the front." For these two mothers with more than two children, it was complicated to get the entire family to the store in ways that were lawful and safe. They therefore traveled less altogether and their mobility was limited to the geography surrounding their apartment community.

\section{Quantitative and Qualitative Mixing}

The use of an interactive mixing model between quantitative and qualitative data sets was employed during focus group discussions (Creswell, 2003; Creswell \& Plano Clark, 2011). Participants demonstrated varying degrees of resistance with the outcomes of the EAAM survey. They clearly noted that waiting for a sufficient level of acculturation to take place was unreasonable because being healthy was imminent. The Photovoice portion illuminated other logics that resisted the fixed structure of time. The following section describes the participants' self-perceptions of their acculturation status, within the areas of assimilation, integration, separation and marginalization, and how these areas related their health related behaviors and practices. The EAAM survey demonstrated low levels of acculturation in assimilation due to low proficiency in English and integration, due to low levels of interactions with the dominant culture. Presumptively, this inhibits access to healthful living, but participants articulated their efforts toward these areas of low acculturation by taking English courses, finding foods from their Burmese diet that were frozen versus fresh.

Separation and marginalization were both rated as high on the EAAM survey. In the area of separation, their lack of networks outside the Burmese community restricted their capacity to influence their healthful living, but qualitative findings demonstrated that healthcare institutions also limited their contributions to their pre-existing healthy food habits. Participants often felt misunderstood with their healthcare providers even with interpretation being furnished. Qualitative themes demonstrated that interpretation was a minimum and that advocacy and a more responsive understanding of an interpreter's skills and doctor's cross-cultural understanding needed to be addressed. 
Table 5

Data mixing-Analysis of Quantitative and Qualitative Components of the study

\begin{tabular}{ll}
\hline Quantitative outcomes/EAAM Survey & Qualitative themes \\
\hline $\begin{array}{l}\text { Assimilation is low because participants don't } \\
\text { know language and its cultural systems well yet }\end{array}$ & $\begin{array}{l}\text { Participants are all taking English courses and } \\
\text { consistently attend }\end{array}$ \\
& $\begin{array}{l}\text { Foods of home country are found and prepared } \\
\text { well. When fresh food is absent, frozen is acquired } \\
\text { as substitute. }\end{array}$ \\
$\begin{array}{ll}\text { Integration is low because participants do not have } \\
\text { friends outside the Burmese community. }\end{array}$ & $\begin{array}{l}\text { A Burmese advocate for seriously ill patients } \\
\text { makes integration attempts at the hospital. His } \\
\text { attempts at integration through agency are not met } \\
\text { with reciprocity from the hospital. }\end{array}$ \\
$\begin{array}{l}\text { Separation is high because participants do not have } \\
\text { friends or networks outside the Burmese } \\
\text { community }\end{array}$ & $\begin{array}{l}\text { Representing their distinct languages and religious } \\
\text { practices, agencies and health care providers use } \\
\text { devices to convince patients that "mere choices" } \\
\text { will satisfy doctor's conception of healthy living. }\end{array}$ \\
$\begin{array}{l}\text { Marginalization is high because the Burmese do } \\
\text { not feel heard by their health care providers }\end{array}$ & $\begin{array}{l}\text { Interpretation in health care settings is necessary, } \\
\text { but advocacy is most central and should be } \\
\text { recognized. }\end{array}$ \\
& $\begin{array}{l}\text { Participants feel empowered when in settings of } \\
\text { Burmese affinity, where experiences are shared and } \\
\text { validated. }\end{array}$ \\
\hline
\end{tabular}

\section{Assimilation}

The outcomes on the EAAM survey for assimilation demonstrated a correlation between years in the U.S. and levels of assimilation. Assimilation suggested that low proficiency would create significant barriers to healthy living. Photovoice findings suggested that accessibility to healthy foods was not a limitation.

Healthy food available. Despite low proficiency in English, participants found foods that were healthy and available in local Asia-Marts. Although halal prepared meats were costly, other foods were affordable and attainable. Families regularly cooked their familiar foods that met their criterion for healthy living, which extend beyond North American conceptions of protein for energy and calcium for good bone development. Specific Burmese foods were equated with healthy skin and anti-aging. Each food not only had a specific and familiar flavor, but a specific nutritional goal.

Language and cultural ambassadors. Participants were cognizant about how "more time" was imbued upon them in healthcare and educational settings. Addressing this central concern of their sponsors and the healthcare settings, participants actively attended English classes unless their work schedules conflicted. They showed a central devotion to acquiring 
English and held high levels of communicative competence. "Understanding the system" was most central and other avenues were examined and executed to understand and acquire what they needed for healthy living.

\section{Integration}

Integration on the survey demonstrated low outcomes for all participants; yet there was a strong resolve by one participant to be a collective advocate for Burmese refugee families in hospitals. Attempts were made to understand the hospital system, so the "clock" was not an inhibiting factor. This participant's attempt to receive timely responses for his sick friends in the emergency room by knowing what questions to ask and following historic procedures was met with hospital staff that were neither timely nor responsive. The participant was deeply troubled that there seemed to be such a passive denial as he met the criterion for being communicatively competent and also, knowledgeable of the hospital system.

\section{Separation}

Separation on the survey demonstrated that participants did not have friends or networks outside their local Burmese community and this became situated in a power conflict in the doctor's office. One participant was troubled by her doctor's suggestion that she follow the food pyramid. In disclosing the halal diet she provided for her two children, the doctor's continued reference of the food pyramid inferred it as the best "choice" for her family. Her efforts to demonstrate how her halal diet fit within the pyramid were dismissed. Her resilience in explaining her conformity within her tradition and within the pyramid was an attempt of being "non-separate," yet the physician's persistent framework positioned her as uncooperative.

\section{Marginalization}

Interpretation was a consistent theme of concern that was shared when one participant shared her photo of the detailed health form she was to complete a priori of a doctor's visit (Figure 5). In healthcare settings, Burmese interpreters were presumed to be skillful and hardworking by providers, but participants were troubled that they moved too swiftly between interpretation tasks, reducing accuracy and responsiveness. This work ethic and interpretation skill sanctioned by the healthcare provider masqueraded for physicians as being accurate, adequate and complete. Participants regarded interpretation as harried, inaccurate, and distant.

Physicians' trusting the interpreter quality made participants feel marginalized when their needs were not conveyed with accuracy, emotion and timeliness. By discussing this photo, each participant recollected a time of misunderstanding and partiality due to poorly conceived interpretation experience in healthcare provider contexts. Together, the participants distilled different logics about accuracy and responsiveness of interpretation. While in most healthcare patient/doctor situations, an interpreter was furnished, the participants claimed interpretation was conceived as a transmission model and met the immediacy needs of the doctor, but not the patient (Freire, 1986; Pochhacker, 2004). This repositioning of agency from patient to interpreter created an expansive power division that made their care reliant on the perceptions and practices of the interpreter. 


\section{Discussion}

The purpose of this study was to explore health perceptions, access and attitudes towards preventive healthcare, and identify individual, cultural and other environmental challenges towards health behaviors and practices among refugees from Burma who now reside in a central Midwest town in the United States. Results showed that the Burmese participants resisted normativity of healthcare provision, pushing on the fixed mental structures of their physicians and healthcare clinics. In other words, the local healthcare system did not reflect the health practices, needs, and concerns of the Burmese. For example, the use of an interpreter was conceived in expediency by healthcare providers, but foreclosed on the immediacy and accuracy of their needs as patients, which was found in a similar study conducted by Kumar (2013). Health care providers presented food pyramids as universalisms, yet participants could all describe foods distinct to their diet and their related health benefits that were not taken into consideration by healthcare providers.

These transmission models of healthcare provision were hierarchical: doctor, interpreter and patient. This particular power structure created disequilibrium that participants challenged by resisting the notion of more time needed to learn English in order to be fully acclimated and acculturated. Through their photographic representations and collaborative analysis of healthy living, they demonstrated their commitment to healthy lives.

Using critical and ecological theories, this study illuminated the disequilibrium of power that the Burmese experienced in their healthcare settings that are built on a normative set of standards. Participants articulated their logics for their diets and the need to be accurate in portraying their healthcare needs. They expanded the notions of normalcy with specific narratives and photos with distinct rationale. Theorizing through these two lenses enabled new definitions of healthy living that expand the notions of healthful living instead of restricting it to the dominant paradigm.

\section{Limitations of the Study}

There are several limitations to this study. There were limitations encountered due to the survey and the interpretation of photos. The original EAAM survey was validated with the use of Asian participants, some of whom were not East Asian. Further, the survey was developed on a university campus and as such, it was represented with many individuals with high levels of education. This can create interpretive concerns as the participant pool differs in the site of study. Furthermore, the use of interpreters adds another layer of complexity to the study. Did the interpreters interpret correctly the intended meaning of the survey questions? Did the researchers understand the intended meaning of the participants? To what extent did cultural differences influence the communication of intended meaning?

The Photovoice protocol can be limiting as photos can be difficult to co-interpret and familiarity with the local context may be not be as developed with the community and the research team (Mejia et al., 2013). Efforts were made with the research team to include input of the participants at all stages to reduce these possibilities.

The small number of participants can be a concern. As stated previously, the quantitative portion was less weighted and provided descriptive data to inform the qualitative portion. As Photovoice participants listen to each other's stories, they help to identify emerging themes and develop the themes. Because of the storytelling and co-construction of meaning involved, groups 
need to be small. Future studies could take into consideration these limitations while exploring follow up questions.

\section{Implications and Next Steps}

This study shows a cultural context in which it is evident that rather than creating spaces for culturally relevant healthcare practices, healthcare providers are more likely to interact with the Burmese newcomers through a fixed mental structure of care. Survey outcomes can place the impetus on institutions to react to levels of acculturation and accommodate based on those outcomes. These accommodations are often made by the institution and conceived in sensitivity and responsiveness, yet these changes may not be inclusive of the voices of the Burmese community. Further, these accommodations attend to incremental changes such as language interpretation, which has limited impact as indicated by this study on trustworthiness between patient and care provider. Surveys however, coupled with interviews or focus group discussion protocol that is participatory in nature has the power to inform institutions to employ different logics about how they may subtractively conceive new Burmese sojourners to the Midwest. As a research collective with and among the Burmese community, we suggest the following.

\section{Training and Practices in Patient Interpretation and Translation}

The hierarchical model of healthcare provider to interpreter to patient needs to be illuminated, so the source message of the patient is central. The transmission model of translation and interpretation simplifies the very complex process of conveying healthcare needs. More time needs to be built into scheduled appointments requiring interpretation, so the power can be resituated to focus on the patient and not the expedience of mere message delivery.

The "pay by the job" for translation and interpretation work needs to be reassessed. Economic incentives drive the speed by which interpreters make their income. This points to the need to have full-time interpreters with benefits in healthcare settings. This will create greater interpreter retention, consistency of care and embedded professional development experiences for healthcare providers to learn about responsive interpretation practices.

Any necessary medical documents need to be furnished to patients prior to appointments with translation resources availed to the patient, so forms are filled out comprehensively and accurately. Additionally, identifying other strategies to solicit information should be explored.

\section{Representation and Interpretation of the Food Pyramid}

In this study, a care provider used the old food pyramid, even though a newer one has been available since 2011. Called ChooseMyPlate, the new nutritional format consists of sections for proteins, grains, vegetables, fruits and dairy ("ChooseMyPlate," 2014). While this food format is more simplified and imbues the notion of choice for nutritional aims, it still articulates a fixed format that does not recognize current dietary practices of the Burmese. Specific representations of what can be on one's plate should be explored with and among specific communities; so Burmese patients can be empowered by their food choices instead of judged for them. 


\section{Conclusion}

The Burmese refugees were agentic in avocation for self, family and community when it came to healthy living. Healthy foods were accessible in Asia-Marts and preparation of their meals met their defined dietary needs and preferences. The healthcare system, including doctor's offices, clinics and hospitals were places of resistance where they troubled the fixed formulas of healthy living. Burmese refugees pushed on the traditional notions of assimilation, integration, separation and marginalization, redefining their methods as creative, collective and instructional to the health care system.

Follow up studies have been established to deepen our understanding as researchers on how institutions mitigate translation and interpretation services for Burmese refugees. Specifically, work is being established to examine the implications of using interpreters and translators in identifying health promotion goals with an ultimate goal of empowering the sojourners from Burma.

\section{References}

Barron, S., \& Ranard, D. (2007). Refugees from Burma: Their backgrounds and refugee experiences. Center for Applied Linguistics, Washington, DC: Cultural Orientation Resource Center.

Barry, D. T. (2001). Development of a new scale for measuring acculturation: The East Asian acculturation measure (EAAM). Journal of Immigrant Health, 3(4), 193-197.

Beiser, M. (2005). The health of immigrants and refugees in Canada. Canadian Journal of Public Health, 96(2), 30-44.

Beiser, M., Hou, F., Hyman, I., \& Tousignant, M. (2002). Poverty, family process, and the mental health of immigrant children in Canada. American Journal of Public Health, 92(2), 220-227.

Bhui, K., Stansfield, S., Hull, S., Priebe, S., Mole, F., \& Feder, G. (2003). Ethnic variations in pathways to and use of specialist mental health services in the UK: Systematic review. British Journal of Psychiatry, 182, 105-116. doi: 10.1192/bjp.02.159

Birman, D., Beehler, S., Harris, E. M., Everson, M. L., Batia, K., Liautaud, J., \& Cappella, E. (2008). International Family, Adult, and Child Enhancement Services (FACES): A community-based comprehensive services model for refugee children in resettlement. American Journal of Orthopsychiatry, 78(1), 121-132.

Bourdieu, P. (1984). Distinction: A social critique of the judgement of taste. Cambridge, MA: Harvard University Press.

Brendler-Lindqvist, M., Norredam, M., \& Hjern, A. (2014). Duration of residence and psychotropic drug use in recently settled refugees in Sweden - A register-based study. International Journal for Equity in Health, 13(1), 116-130. doi: 10.1186/s12939-0140122-2

Burmese American Community Institute. (2014). The Burmese population in the U.S., Indiana and Indianapolis. Retrieved from http://www.baci-indy.org/resources/burmese-refugeepopulation-in-the-us

Canales, G. (2013). Transformative, mixed methods checklist for psychological research with Mexican Americans, Journal of Mixed Methods Research. 7(1), 6-21. doi: $10.1177 / 1558689812446022$ 
Center for Nutrition Policy and Development. (2005). My pyramid - Getting started. Retrieved from http://www.choosemyplate.gov/food-groups/downloads/MyPyramid_Getting_ Started.pdf

Chambers, N., \& Ganesan, S. (2005). Refugees in Canada. In N. Waxler-Morrison, J. Anderson, E. Richardson \& N. Chambers (Eds.), Cross-cultural caring: A handbook for health professionals (2nd ed., pp. 289-322). Vancouver, BC: University of British Columbia Press.

ChooseMyPlate. (2014). Retrieved from http://www.choosemyplate.gov/about.html

Creswell, J. W. (2003). Research design: Qualitative, quantitative, and mixed methods approaches (2nd ed.). Thousand Oaks, CA: Sage Publications.

Creswell, J. W. (2007). Qualitative inquiry \& research design: Choosing among five approaches (2nd ed.). Thousand Oaks, CA: Sage Publications.

Creswell, J. W., \& Plano Clark, V. L. (2007). Designing and conducting mixed methods research. Thousand Oaks, CA: Sage Publications.

Creswell, J. W., \& Plano Clark, V. L. (2011). Designing and conducting mixed methods research (2nd ed.). Los Angeles, CA: Sage Publications.

Crotty, M. (1998). The foundations of social research: Meaning and perspective in the research process. Thousand Oaks, CA: Sage Publications.

DéVoretz, D. J., Pivnenko, S., \& Beiser, M. (2004). The economic experiences of refugees in Canada. RIIM Working Paper Series (Vol. No. 04-04). Vancouver, BC: Vancouver Centre for Excellence.

Dharod, J. M., Croom, J. E., \& Sady, C. G. (2013). Food insecurity: Its relationship to dietary intake and body weight among Somali refugee women in the United States. Journal of nutrition education and behavior, 45(1), 47-53.

Ellis, B. H., MacDonald, H. Z., Klunk-Gillis, J., Lincoln, A., Strunin, L., \& Cabral, H. J. (2010). Discrimination and mental health among Somali refugee adolescents: The role of acculturation and gender. American Journal of Orthopsychiatry, 80(4), 564.

Exodus Social Services. (2014). The life ahead: Learn more. Retrieved from http://www.exodusrefugee.org/news.html

Fairclough, N. (2001). Language and power. New York, NY: Longman.

Fazel, M., Wheeler, J., \& Danesh, J. (2005). Prevalence of serious mental disorder in 7000 refugees resettled in western countries: A systematic review. The Lancet, 365(9467), 1309-1314.

Fielding, J., Teutsch, S., \& Breslow, L. (2011). A framework for public health in the United States. Public Health Reviews, 32(1), 174-189.

Flynn, P. M., Foster, E. M., \& Brost, B. C. (2011). Indicators of acculturation related to Somali refugee women's birth outcomes in Minnesota. Journal of Immigrant and Minority Health, 13(2), 224-231.

Foucault, M. (1995). Discipline and punish: The birth of the prison (2nd Vintage Books ed.). New York, NY: Vintage Books.

Freire, P. (1986). Pedagogy of the oppressed. New York, NY: Seabury Press.

Geltman, P. L., Adams, J. H., Penrose, K. L., Cochran, J., Rybin, D., Doros, G., \& PaascheOrlow, M. (2014). Health literacy, acculturation, and the use of preventive oral health care by Somali refugees living in Massachusetts. Journal of Immigrant and Minority Health, 16(4), 622-630.

Greene, J. (2007). Mixed methods in social inquiry (1st ed.). San Francisco, CA: Jossey-Bass. 
Grisaru, N., Irwin, M., \& Kaplan, Z. (2003). Acute psychotic episodes as a reaction to severe trauma in a population of Ethiopian immigrant to Israel. Stress and Health, 19, 241-247. doi: $10.1002 /$ smi.976

Johnson, C. E., Ali, S., \& Shipp, M. P. (2009). Building community-based participatory research partnerships with a Somali refugee community. American Journal of Preventative Medicine, 37(3S1), 230-236. doi: 10.1016/j.amepre.2009.09.036

Kimbrough, W., Saliba, V., Dahab, M., Haskew, C., \& Checchi, F. (2012). The burden of tuberculosis in crisis-affected populations: A systematic review. The Lancet: Infectious Disease, 12, 950-965.

Koh, L. C., Liamputtong, P., \& Walker, R. (2013). Burmese refugee young women navigating parental expectations and resettlement. Journal of Family Studies, 19(3), 297-305.

Kopecky, D. (2011). Foucault, governmentality, neoliberalism and adult education-perspectives on normalization of social risk. Journal of Pedagogy/Pedagogický Casopis, 2(2), 246262. doi: 10 .2478/v10159-011-0012-2

Kumar, R. (2013). Negotiating healthcare structures in the United States: Reassessing resettlement through Burmese refugee voices. (Doctoral dissertation). Retrieved from http://docs.lib.purdue.edu/dissertations/AAI3604941/

Lewis, M., Simmons, G., \& Fennig, C. (2015). Ethnologue: Languages of the World Myanmar. Retrieved from https://www.ethnologue.com/country/MM/languages

Li, H. Z., \& Browne, A. J. (2000). Defining mental health illness and accessing mental health care services: Perspectives of Asian Canadians. Canadian Journal of Community Mental Health, 19, 143-159.

Lin, K. M., \& Cheung, F. (1999). Mental health issues for Asian Americans. Psychiatric Services, 50(6), 774-780.

Lobou, P. A., \& Moser, K. S. (2004). Screening of immigrants and refugees for pulmonary tuberculosis in San Diego county, California. CHEST, 126, 1777-1782.

McMillan, J. H., \& Schumacher, S. (1997). Research in education: A conceptual introduction (4th ed.). New York, NY: Longman USA.

Mejia, P. A., Quiroz, O., Morales, Y., Ponce, R., Limon Chavez, G., \& Olivera y Torre, E. (2013). From madres to mujeristas: Latinas making change with Photovoice. Action Research, 11(4), 301-321. doi: 10.1177/1476750313502553

Mertens, D. M. (2003). Mixed methods and the politics of human research: The transformativeemancipatory approach. In A. Tashakkori \& C. Teddlie (Eds.), Handbook of mixed methods in social and behavioral sciences (pp. 135-164). Thousand Oaks, CA: SAGE.

Mertens, D. M. (2009). Transformative research and evaluation. New York, NY: Guilford Press.

Morrow, R. A., \& Brown, D. D. (1994). Critical theory and methodology. Thousand Oaks, CA: Sage Publications.

Nakash, O., Nagar, M., Shoshani, A., Zubida, H., \& Harper, R. A. (2012). The effect of acculturation and discrimination on mental health symptoms and risk behaviors among adolescent migrants in Israel. Cultural Diversity and Ethnic Minority Psychology, 18(3), 228.

Pochhacker, F. (2004). Introducing interpreting studies. New York, NY: Routledge.

Rondinelli, A. J., Morris, M. D., Rodwell, T. C., Moser, K. S., Paida, P., Popper, S. T., \& Brouwer, K. C. (2011). Under-and over-nutrition among refugees in San Diego County, California. Journal of Immigrant and Minority Health, 13(1), 161-168. 
Shepard, J. (1992). Post-traumatic stress disorder in Vietnamese women. In E. Cole, O. M. Espin \& E. D. Rothblum (Eds.), Refugee women and their mental health: Shattered societies, shattered lives (pp. 281-296). New York, NY: Haworth Pub.

Smith, E. (2003). Habitus and situation for learning: An ecology. British Journal of Sociology of Education, 24(4), 463-470.

Stewart, M., Makwarimba, E., Barnfather, A., Letourneau, N., \& Neufeld, A. (2007). Researching reducing health disparities: Mixed-methods approaches. Social Science and Medicine, 66, 1406-1417.

Sweetman, D., Badiee, M., \& Creswell, J. W. (2010). Use of the transformative framework in mixed methods studies. Qualitative Inquiry, 16(6), 441-454. doi: 10.1177/ 1077800410364610

Thurston, W. E. \& McGrath, A. (1993). "With two pennies in my pocket, I just feel not so helpless": A report on the mental and occupational health promotion needs of immigrants in Calgary. Calgary, AB: University of Calgary, Department of Community Health Sciences.

United Nations High Commission for Refugees. (2010). Convention and protocol relating to the status of refugees (pp. 1-52). Geneva, Switzerland.

Uppaluri, A., Naus, M., Heywood, N., Brunton, J., Kerbel, D., \& Wobeser, W. (2002). Effectiveness of the immigration medical surveillance program for tuberculosis in Ontario. Canadian Journal of Public Health, 93(2), 88-91.

Vang, C. Y., \& Mong Trieu, M. (2014). Invisible newcomers: Refugees from Burma/Myanmar and Bhutan in the United States. Washington, DC: Asian and Pacific Islander Scholarship Fund.

Wang, C. C., \& Burris, C. A. (2004). Family, maternal, and child health through Photovoice. Maternal and Child Health Journal, 8(2), 95-102.

Wang, C. C., Morrell-Samuels, S., Hutchison, P. A., Bell, L., \& Pestronk, R. M. (2004). Flint Photovoice: Community building among youths, adults and policymakers. American Journal of Public Health, 94(6), 911-913.

Wang, C. C., Yi, W. K., Tao, Z. W., \& Carovano, K. (1998). Photovoice as a participatory health promotion strategy. Health Promotion International, 13(1), 75-86.

Zacharadias, M., Scott, S., \& Barrett, M. (2013). Methodological implications of critical realism for mixed-methods research. MIS Quarterly, 37(3), 855-879. 


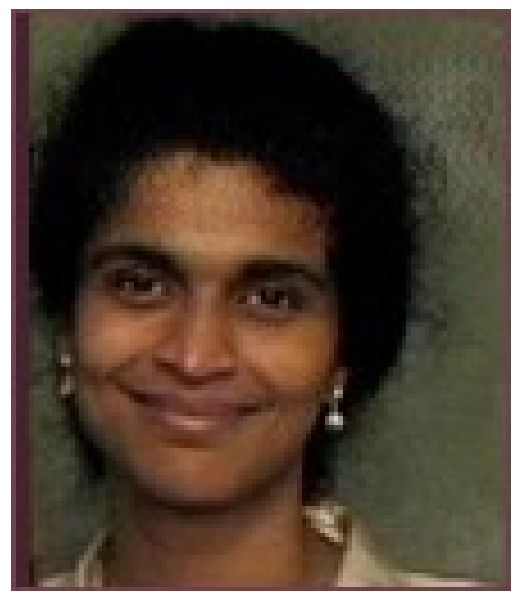

Dr. Suneeta Kercood is a Professor of Education at Butler University with a background in education and experience in the areas of disabilities, psychology, and applied behavior analysis. Dr. Kercood's research interests include: antecedent interventions and preventive care in education and health for special populations, application of applied behavior analysis in global health and education issues, use of technology in professional preparation programs, developing online and distance education teaching programs, and universal design. Dr. Kercood is a recipient of a Fulbright senior research scholar award to study disability and health issues in India, and is also pursuing projects in the US involving training programs to improve oral health care, identifying socio-ecological factors related to health of special populations, and their challenges/barriers in communicating with community pharmacists. Dr. Kercood is also a nationally certified EMT, trained in wilderness rescue, and regularly volunteers to provide medical/health services during national and local disasters.

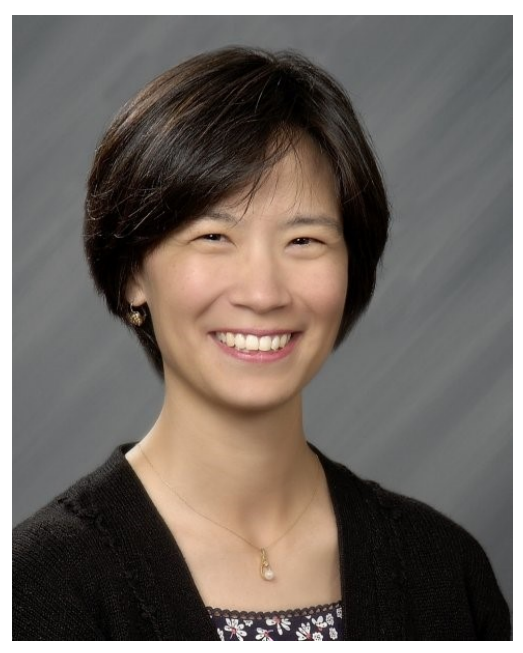

Trish Morita-Mullaney, Ph.D., is an Assistant Professor in English Language Learning (ELL) at Purdue University in West Lafayette, IN. Trish is a licensed K-12 teacher, coach and administrator from Arizona and Indiana where she taught and led in ELL adult education, middle and elementary school. She serves as the President of the Indiana Chapter for Teachers of English to Speakers of Other Languages. Her research focuses on the intersections between language learning, gender and race and how this informs the identity acts of educators of bilingual students. Guided by critical and feminist thought, she examines how these overlapping identities inform the logics of educational decision making for bilingual students. 


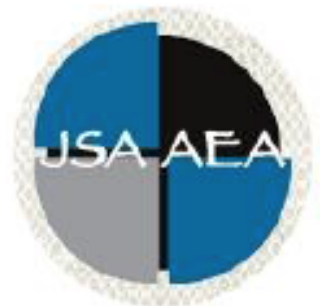

Volume 10 (2015)

\title{
Journal of Southeast Asian American
}

\section{Education and Advancement}

\author{
www.JSAAEA.org
}

\section{Editor}

Dr. Wayne E. Wright

Purdue University

\section{Associate Editors}

Dr. Chhany Sak-Humphry

University of Hawaii at Manoa

Dr. Phitsamay Sychitkokhong Uy

University of Massachusetts, Lowell

\section{Book Review Editor}

Dr. Vichet Chhuon

University of Minnesota

\section{Creative Works Editor \\ Bryan Thao Worra \\ Lao Assistance Center}

\section{Journal Manager \\ Marshall Klassen \\ Purdue University}

\section{Editorial Review Board}

Dr. Steve Arounsack

California State University, Stanislaus

Dr. Sovicheth Boun

The State University of New York at Fredonia

Dr. George Chigas

University of Massachusetts, Lowell

Dr. Hien Duc Do

San Jose State University

Dr. Sophal Ear

Occidental College

Dr. Jeremy Hein

University of Wisconsin, Eau Claire

Dr. Nancy H. Hornberger

University of Pennsylvania

Dr. Peter Nien-Chu Kiang

University of Massachusetts, Boston

Dr. Ha Lam

Eastern Mennonite University
Dr. Carl L. Bankston III Tulane University

Dr. Phala Chea

Lowell Public Schools

Dr. Loan Dao

University of Massachusetts, Boston

Dr. Changming Duan

University of Missouri, Kansas City

Dr. Sothy Eng

Lehigh University

Dr. Vincent K. Her

University of Wisconsin, Eau Claire

Dr. Peter Tan Keo

New York University

Dr. Kevin K. Kumashiro

University of San Francisco

Dr. Ravy Lao

California State University, Los Angeles 
Dr. Jonathan H. X. Lee

San Francisco State University

Dr. Monirith Ly

Royal University of Phnom Penh

Dr. Bic Ngo

University of Minnesota

Dr. Leakhena Nou

California State University, Long Beach

Dr. Mark Pfeifer

SUNY Institute of Technology

Dr. Loan T. Phan

University of New Hampshire

Dr. Kalyani Rai

University of Wisconsin, Milwaukee

Dr. Cathy J. Schlund-Vials

University of Connecticut, Storrs

Dr. Nancy J. Smith-Hefner

Boston University

Dr. Yer J. Thao

Portland State University

Dr. Monica M. Trieu

Purdue University

Dr. Silvy Un

Saint Paul Public Schools

Dr. Terrence G. Wiley

Center for Applied Linguistics
Dr. Stacey Lee

University of Wisconsin, Madison

Dr. Sue Needham

California State University, Dominguez Hills

Dr. Max Niedzwiecki

Daylight Consulting Group

Dr. Clara Park

California State University, Northridge

Dr. Giang Pham

University of Massachusetts

Dr. Karen Quintiliani

California State University, Long Beach

Dr. Angela Reyes

Hunter College, The City University of New York

Dr. Fay Shin

California State University, Long Beach

Dr. Christine Su

Ohio University

Dr. Alisia Tran

Arizona State University

Dr. Khatharya Um

University of California, Berkeley

Dr. Linda Trinh Vo

University of California, Irvine

Dr. Yang Sao Xiong

University of Wisconsin-Madison

Dr. Zha Blong Xiong

University of Minnesota

\section{Doctoral Student Editorial Review Board}

\author{
Virak Chan \\ University of Texas at San Antonio \\ Annie BichLoan Duong \\ San Joaquin County Office of Education \\ Hoa Nha Nguyen \\ Boston College \\ Malaphone Phommasa \\ Marshall University \\ Molly Wiebie \\ The University of Texas at Austin
}

\author{
Keo Chea-Young \\ University of Pennsylvania \\ Dung Minh Mao \\ University of Minnesota \\ Thien-Huong Ninh \\ University of Southern California \\ Krissyvan Truong \\ Claremont Graduate University \\ Soua Xiong \\ San Diego State University \& \\ Claremont Graduate University
}

Anna H. Yang

University of Georgia 